\title{
Desemparedamento escolar em contexto pandêmico: experiências da aprendizagem ao ar livre na educação infantil
}

Gisele Rodrigues Soares ${ }^{1}$ Simoni Cezimbra Porto ${ }^{2}$

\begin{abstract}
Resumo:
O objetivo deste artigo é analisar as ações desenvolvidas por uma escola pública de educação infantil no período anterior ao contexto pandêmico para iniciar uma proposta pedagógica de desemparedamento. Avaliamos em que medida a proposta pode se tornar adequada para o retorno do atendimento presencial em escolas dessa etapa de ensino. A partir da metodologia de pesquisa autobiográfica, refletimos sobre quais são as possibilidades e os desafios para a continuidade da proposta nesta escola do ponto de vista da gestão escolar. Os benefícios de uma organização das experiências das crianças ao ar livre são abordados em estudos teóricos e documentos legais através dos conceitos de espaço e de desemparedamento da infância. Concluímos que será preciso garantir um retorno seguro, na perspectiva dos protocolos sanitários e do distanciamento entre os sujeitos, porém, sem esquecer da oferta de um espaço de acolhimento e de aprendizagem qualificado para as crianças. Nesse sentido, o uso dos espaços externos e da proposta de desemparedamento, adaptado ao contexto, surge como uma possibilidade viável, pertinente e significativa.
\end{abstract}

\section{Palavras-chave:}

Educação infantil. Espaço. Desemparedamento da infância. Pandemia.

\section{Unwalling in schools during the pandemics: outdoors learning experiences with Child Education}

\footnotetext{
Abstract:

This paper aims to analyze a group of initiatives developed at a public child education institution in a moment prior to the pandemics as a possible launcher for a pedagogical initiative of "unwalling" (taking the children to spend more time outdoors). We explore to which extent this very same project

1 Mestre em Educação. Universidade Federal do Rio Grande do Sul. Coordenadora da Educação Infantil na Secretaria Municipal de Educação de Porto Alegre. E-mail: gisele-rsoares@educar.poa.br ORCID iD: https://orcid.org/0000-0003-1624-4686. 2 Especialista em Pedagogias do Corpo e da Saúde. Universidade Federal do Rio Grande do Sul. Diretora da Escola Municipal de Educação Infantil Jardim de Praça EMEI JP Meu Amiguinho, em Porto Alegre. E-mail: simoni-cezimbraporto@educar.poa. br ORCID iD: https://orcid.org/0000-0001-6420-3139.
} 
may be fitting in the near future, when children the same age go back to face-to-face education. Through an autobiographical research method, we meditate on the challenges and possibilities for continuing the project at the same school from a managerial point of view. The benefits of organizing children's experience outdoors are discussed in theoretical studies and legal documents, while we explore the ideas of space and unwalling during childhood. We end off with the belief that it is mandatory to guarantee a safe return for all students, following all health protocols and promoting social distancing between students. Nevertheless, we must not overlook the importance of providing a high-quality and welcoming learning space for children, as in such a context the use of open spaces and the idea of "unwalling", if duly adapted, emerges as a viable, relevant and meaningful possibility.

\section{Keywords:}

Child education. Space. Unwalled childhood. Pandemics.

\section{Desemparedamiento en la escuela en contexto pandémico: expe- riências de aprendizaje al aire libre en la Educación Infantil}

\section{Resumen:}

El objetivo de este artículo es analizar las acciones desarrolladas por una escuela publica de Educación Infantil, en el período previo al contexto pandémico, para empezar una propuesta pedagógica de desemparedamiento. Evaluamos hasta qué punto la propuesta puede volverse adecuada para el regreso de las clases presenciales en las escuelas en esta etapa de enseñanza. A partir de la metodología de la investigación autobiográfica, reflexionamos sobre cuáles son las posibilidades y los desafíos para la continuidad de la propuesta en esta escuela desde el punto de vista de la gestión escolar. Los benefícios de organizar las experiencias de los niños al aire libre se abordan en estudios teóricos y documentos legales brasileños, a través de los conceptos de espacio y desemparedamiento infantil. Concluimos que será necesario garantizar un regreso seguro, en la oferta de un espacio de aprendizaje acogedor y calificado para los niños. En este sentido, el uso de espacios externos y la propuesta de desemparedamiento adaptada al contexto, aparece como un posibilidad viable, relevante y significativa.

\section{Palabras clave:}

Educación infantil. Espacio. Desemparedamiento de la infancia. Pandemia.

\section{Da relevância desse tema, agora mais do que nunca}

Após um longo período de isolamento social imposto pela pandemia da COVID-19, o debate sobre o retorno das crianças ao espaço escolar nos conduz a vários questionamentos sobre quais seriam as formas mais adequadas de retomar o convívio escolar, especialmente na educação infantil. A discussão não se restringe a quais protocolos sanitários precisam ser respeitados - o que por si só é importante e influencia a ação pedagógica no cotidiano com bebês, crianças bem pequenas e crianças pequenas. Para além disso, o contexto nos provoca a (re)pensar como e onde acolher esses meninos e meninas de forma mais segura e, ainda assim, promotora de experiências que garantam a interação e as brincadeiras próprias dessa etapa.

Entre os elementos para a promoção desse acolhimento está o planejamento e a organização dos espaços da escola. Consideramos, sobretudo, as áreas externas, como pátios, pracinhas e praças do entorno escolar, enquanto locais que podem possibilitar um distanciamento mais seguro. A concepção de "desemparedamento da infância" nos insere nesse debate. O objetivo deste artigo é, 
portanto, analisar as ações desenvolvidas por uma escola pública de educação infantil no período anterior ao contexto pandêmico para iniciar uma proposta pedagógica de desemparedamento, considerando a importância desse processo para o desenvolvimento das crianças a qualquer tempo, e evidenciando como uma escola "desemparedada" pode promover um retorno mais qualificado das crianças ao espaço escolar.

Tomamos o conceito de "espaço escolar" (ZABALZA, 1991; FORNERO, 1998) enquanto elemento potencialmente pedagógico quando planejado e articulado de modo a favorecer o protagonismo das crianças. Tal conceito é estendido para compreender os "espaços externos" na escola de educação infantil como um lugar de aprender, considerando os benefícios da natureza no desenvolvimento infantil e o próprio conceito de "desemparedamento da infância" (TIRIBA, 2010). Os documentos normativos brasileiros para a oferta da educação infantil em nível nacional podem servir como referência para a qualificação dos espaços externos escolares. Incluímos aqui os Parâmetros Básicos de Infraestrutura para a Educação Infantil (BRASIL, 2008), os Indicadores de Qualidade para a Educação Infantil (BRASIL, 2009a), a Resolução CNE/CEB n. ${ }^{\circ}$, de 17 de dezembro de 2009 que fixa as Diretrizes Curriculares Nacionais para a Educação Infantil/DCNEI (BRASIL, 2009b) e a Base Nacional Comum Curricular/BNCC (BRASIL, 2017).

Nossa análise está circunscrita a uma escola pública de educação infantil situada em Porto Alegre (RS). Metodologicamente, lançamos mão da "pesquisa autobiográfica" (JESUS; TASSONI, 2017; NEVES, 2010) partindo do ponto de vista da gestão escolar personificada pelas funções de Diretora da instituição e de Coordenadora na Secretaria Municipal de Educação (SMED). Através de processos formativos com a equipe de professores e articulações da gestão com o seu entorno, a escola já experienciou práticas pedagógicas ao ar livre com as crianças (antes do contexto pandêmico) e atualmente se coloca diante do desafio da continuidade dessas práticas para o acolhimento das crianças nos espaços externos enquanto se restabelece o retorno presencial. Entendemos que essa discussão possa se constituir em elemento de estudo de pesquisadores(as) interessados(as) no aprofundamento quanto ao processo de desemparedamento na escola infantil enquanto construção coletiva, assim como para que equipes escolares possam repensar seus espaços externos, buscando um retorno presencial do atendimento na educação infantil com qualidade.

\section{Aspectos teóricos que nos fortalecem, aspectos legais que nos subsidiam}

Reconhecendo a importância da sustentação teórica para a reflexão acerca do desemparedamento, primeiramente apresentaremos nossas concepções de espaço. Buscamos ressaltar a necessidade de retomar esse elemento que, embora não seja uma novidade, ganha um novo sentido enquanto foco de discussão acadêmica para a educação nesse momento. Assim, entendemos o "espaço" em uma instituição de educação infantil como "algo que nos penetra e condiciona (facilitando ou dificultando) nosso próprio desenvolvimento pessoal e coletivo" (ZABALZA, 1991, p. 6, tradução nossa). Fornero (1998), citando também Zabalza (1987 apud FORNERO, 1998), inclui a ideia de "estrutura de oportunidades" na definição de espaço. Tal estrutura pode se tornar estimulante ou limitadora de acordo com as condições de interação e integração oferecidas. Além disso, a autora, ao definir o conceito de "espaço", também considera a ideia de "ambiente", que significa que há percepções que nos são desencadeadas em cada espaço, nos provocando sensações, sejam elas de medo ou curiosidade, irritabilidade ou calma, atividade ou apatia, mas nunca a indiferença (FORNERO, 1998).

Se a disposição dos espaços interfere em como nos sentimos e agimos, seguramente precisamos repensar os ambientes escolares constantemente, para que se tornem agradáveis, acolhedores e promotores de oportunidades de aprendizagens desafiadoras, estimulantes e integradoras. Com alguma frequência, sobretudo em grandes metrópoles urbanas, onde áreas públicas de lazer 
são vistas como perigosas, os espaços escolares oferecem a única oportunidade que as crianças têm para vivenciar experiências que despertem a curiosidade e a imaginação, principalmente em relação à natureza (BROWN, 2006).

Sá e Werle (2017), baseados em um estudo a partir de dados do Censo Escolar 2011³, revelam que apenas $0,6 \%$ das escolas de educação básica naquele ano (entre as públicas, privadas, rurais e urbanas) contavam com uma infraestrutura escolar considerada adequada e capaz de atingir uma educação de qualidade. Ao realizar uma pesquisa a partir da metodologia do "estado da arte" com teses e dissertações brasileiras defendidas entre 2003 e 2013, os autores destacam uma contradição: apesar de pesquisas reconhecerem o quanto o espaço físico pode melhorar o desempenho dos estudantes, não há publicações suficientes a respeito da infraestrutura escolar (SÁ; WERLE, 2017). Embora reconheçamos a importância e a necessidade de continuar havendo estudos sobre como aproveitar melhor os espaços internos das escolas para além da sala-referência ${ }^{4}$, o presente artigo objetiva ressaltar a compreensão de que as áreas externas são uma parte importante de uma proposta pedagógica em uma instituição de educação infantil.

Com frequência, em acompanhamentos pedagógicos e formativos, esbarramos na realidade de algumas escolas: muitas vezes há alguns "muros" que precisamos de alguma forma superar (e "pular"). Esses "muros" impedem a qualificação da proposta pedagógica do "desemparedamento": nos referimos às paredes (grades, telas, muretas), sejam elas concretas ou simbólicas, pois separam os grandes dos pequenos (CARVALHO; FOCHI, 2016); separam os tempos, espaços e modos mais "adequados" para as crianças viverem suas experiências; separam a hora de brincar da hora de aprender; separam o mundo real "lá de fora", à espera de ser explorado e investigado, pois se presume que existe concentração apenas entre "quatro paredes". No estudo dos autores Carvalho e Fochi (2016, p. 162), as crianças observadas e escutadas em uma escola de educação infantil sinalizaram que há uma "vida que 'pulsa' fora dos limites da sala-referência". Analisando o relato de uma dessas crianças, que se apresenta curiosa em enxergar para o "montão de coisas acontecendo" através das janelas da sua sala, os autores afirmam:

Realmente fora dos espaços internos das instituições acontecem muitas coisas, "passam professoras, passam as filas para o lanche, passam os pais, os pequenos para a praça", e, além disso, ainda é possível ver "os passarinhos comendo grama”. O menino aborda vida e educação em sua narrativa. Ele evidencia o dinamismo das relações sociais que são estabelecidas para além das paredes de sua sala, ensinando que as crianças precisam de mais tempo e de mais espaço para que possam protagonizar a vida na escola. (CARVALHO; FOCHI, 2016, p. 162).

Diante dessa afirmação, buscamos referências para o planejamento dos espaços físicos escolares em algumas normativas e orientações nacionais de modo a amparar o debate do ponto de vista legal. Os Parâmetros Básicos de Infraestrutura para Instituições de Educação Infantil, de 2008, publicado pelo MEC/SEB descrevem algumas sugestões para um projeto de qualidade de infraestrutura física para as crianças na faixa etária de creches e pré-escola. Deste documento destacamos a prerrogativa de que o ambiente da educação infantil deve ser preparado pelo(a) professor(a) junto com as crianças, de modo que o espaço esteja organizado para ser periodicamente ressignificado e transformado (BRASIL, 2008), tornando-se

promotor de aventuras, descobertas, criatividade, desafios, aprendizagem e que facilite a interação criança-criança, criança-adulto e deles com o meio ambiente. O espaço lúdico infantil deve ser dinâmico, vivo, "brincável”, explorável, transformável e acessível para todos. (BRASIL, 2008, p. 8).

3 Estudo coordenado pelo pesquisador Joaquim José Soares Neto (2013).

4 Espaços internos como outras salas multiusos, espaços de circulação, refeitórios e até a relação das crianças com o que acontece nas salas administrativas escolares. 
Ao sugerir que as escolas estejam preparadas para receber crianças, famílias e profissionais no retorno presencial na educação infantil, isso de forma alguma representa uma concepção de que tudo esteja pronto e fixado. Pelo contrário, reconhecemos que há transformações no ambiente que precisam envolver e convidar à participação viva e dinâmica das crianças, como apontam os parâmetros citados (BRASIL, 2008). Quando somente o adulto desenvolve esse planejamento, corre-se o risco de restringir a potencialidade desses locais. Nesse sentido, Bruner (2013) afirma o quanto é importante as crianças reconhecerem o espaço como delas e de seus pares, onde haja lugares para estarem em pequenos ou grandes grupos (ou mesmo para estarem sozinhas) e que convidem a diferentes propostas, afinal, "[u]m bom espaço tem diversos lugares" (BRUNER, 2013, p. 145).

É preciso oferecer uma variedade de possibilidades nesses espaços, promovendo a criação de diferentes brincadeiras e interações por parte das crianças e, principalmente, incentivando o desenvolvimento da autonomia na escolha entre a circulação dessas possibilidades. Horn (2003) visualiza essa descentralização do adulto, ocorrida nos espaços externos, como um elemento de aprendizado da autonomia, que só é garantido em ambientes que promovem esse "desapego", com possibilidades de aprendizagens sem sua intermediação direta.

Assim como já observamos uma realidade nas instituições pelas quais trabalhamos enquanto docentes ou em acompanhamentos pedagógicos e formativos que realizamos, também Horn (2014), investigando o uso dos espaços em escolas brasileiras, observou ser comum o confinamento das crianças nos prédios, além da privação climática (muito sol, muito frio ou muita chuva). A autora afirma que era raro ver crianças subindo em árvores, brincando com água, se sujando com areia, já que atividades com lápis e papel em mesas seriam consideradas mais importantes.

Buscando elementos que perpassam o debate dos espaços externos e suas potencialidades enquanto lugar para aprendizagens sobre o mundo natural, encontramos no artigo $9^{\circ}$ da Resolução n. 5/09 (BRASIL, 2009b), que aprova as DCNEI/2009, a afirmação de que as práticas pedagógicas devem promover: "[a] interação, o cuidado, a preservação e o conhecimento da biodiversidade e da sustentabilidade da vida na Terra, assim como o não desperdício dos recursos naturais" (BRASIL, 2009b). Nesse sentido, entendemos que ultrapassar as paredes da sala e ocupar as áreas abertas da escola com as crianças é o primeiro passo para o desemparedamento da infância. O segundo passo é reconhecer as crianças como seres da natureza. Tiriba (2010) afirma que a educação infantil tem o papel de ensinar a cuidar da Terra. Considerando o nosso compromisso com a preservação da vida no planeta, é possível afirmar que "sol, ar puro, água, terra, barro, areia são elementos/ condições que devem estar presentes no dia a dia de creches e pré-escolas" (TIRIBA, 2010, p. 7). A escola, assim, atua envolvendo as crianças no seu próprio processo de humanização, de forma ativa, porque as conecta com esses elementos da sua composição enquanto um ser da natureza, como também atua apresentando sistematizações sobre os conhecimentos do mundo natural, elaborados historicamente, desenvolvendo uma consciência crítica no que se refere às relações e ações humanas no meio ambiente (SPINELLI; ZUCCO; EUZÉBIO, 2020).

Sendo assim, nos aliamos à BNCC/2017 ao assumir a relação com a natureza como uma necessidade e como um direito das crianças. A Base (BRASIL, 2017), reconhecendo as interações e brincadeiras como eixos das propostas pedagógicas (DCNEI/2009), entende que, na educação infantil, as ações docentes com intencionalidade educativa promovem aprendizagens para as crianças através da organização curricular com os "Campos de Experiência". Além disso, a BNCC (BRASIL, 2017) apresenta os seis direitos de aprendizagem e desenvolvimento para as crianças dessa etapa, e é a partir desses direitos que nos propomos a destacar as relações possíveis com as experiências do mundo natural. Assim, as crianças devem: (1) "conviver" (cotidianamente, ao invés de periodicamente, com os elementos naturais, diversificando entre momentos em que estejam acompanhadas ou não de outras crianças e adultos); (2) "brincar" (com diversos tempos, espaços, materiais e parceiros que privilegiem o contato com brinquedos que sejam e estejam no próprio mundo natural); (3) "participar" (de forma ativa, viva e dinâmica da organização e transformação 
dos espaços da escola, incluindo os das áreas externas); (4) "explorar" (diferentes texturas, cheiros, relações e transformações, utilizando os espaços e elementos encontrados do lado de fora da sala como objeto de curiosidade, investigação e criação de hipóteses); (5) "expressar" (através de diferentes linguagens, inclusive corporalmente, seus questionamentos, emoções, opiniões e descobertas sobre o mundo que os cercam); (6) "conhecer-se" (enquanto seres da natureza, no cuidado e no pertencimento a um contexto que é social, cultural e também natural).

Portanto, um espaço externo precisa ser bonito, arejado, ensolarado e oferecer conforto térmico, acústico e visual (TIRIBA, 2010) e, além disso, seu uso pode extrapolar os tempos tão frequentemente limitados e restritos por separações entre turmas, faixas etárias e momentos da rotina da Educação Infantil (FERNANDES; ELALI, 2008). As interações entre as crianças nos pátios das escolas também perpassam pelas escolhas e disposição dos brinquedos e dos materiais, em que a quantidade, a qualidade e a diversidade de possibilidades para o brincar e explorar interferem nas relações sociais entre as crianças, eventualmente desencadeando ora alguma disputa, ora alguma dispersão (FERNANDES; ELALI, 2008).

No mesmo ano em que as DCNEI/2009 foram publicadas, também obtivemos os Indicadores da Qualidade na Educação Infantil (BRASIL, 2009a), que se caracterizam por uma sistematização e detalhamento dos Parâmetros Nacionais de Qualidade para a Educação Infantil (BRASIL, 2006), traduzindo-se como um instrumento de autoavaliação da qualidade das instituições de educação infantil. Sobre os materiais e brinquedos dispostos ao alcance das crianças, para exploração e manuseio com autonomia, os Indicadores da Qualidade na Educação Infantil (2009a) afirmam a importância de considerar

a forma de apresentá-los às crianças, como são guardados e conservados, se podem ser substituídos quando danificados, [já que] são aspectos relevantes para demonstrar a qualidade do trabalho de cuidar e educar desenvolvido na instituição. (BRASIL, 2009a, p. 48).

Enquanto espaço para a promoção de desafios motores, os pátios escolares geralmente refletem a preocupação dos adultos sobre a segurança das crianças que, embora seja um elemento necessário e importante, frequentemente acaba por privá-las de experimentarem e vivenciarem novos desafios. Barros (2018) aponta que a segurança em excesso impede as crianças de se desenvolverem e que ambientes livres de risco podem ocasionar ameaças maiores futuramente. A autora sinaliza a necessidade de planejar espaços que provoquem tais desafios, reconhecendo a existência de alguns "riscos benéficos" que ensinam as crianças sobre a livre escolha, as ajudam a dimensionar consequências, provocam situações em que ela vai precisar lidar com os seus limites, superá-los e, assim, desenvolver a autoconfiança (BARROS, 2018). Nessa perspectiva, o risco (benéfico) é um elemento fundamental do crescimento e do desenvolvimento, pois aprendemos a partir do encontro com o novo. Nesse sentido, defendemos que os bebês, enquanto aqueles que mais têm seus tempos limitados ao ar livre devido a um eventual excesso de segurança, também sejam vistos como sujeitos potentes para brincar, explorar e se desafiar nos pátios escolares.

Diante dos aspectos discutidos, é possível pensar que o processo de desemparedar as crianças começa pelo processo de "desemparedar-se" enquanto profissionais que atuam na docência com bebês, crianças bem pequenas e crianças pequenas. Implica reconhecer a natureza como um "espaço de aprender" pela experiência. Um espaço e um tempo para contemplar, explorar, investigar, compreender, questionar, brincar livre, relaxar, se exercitar, ouvir, ler ou contar histórias, desenhar e pintar, plantar, para, enfim, viver a vida cotidiana escolar "lá fora".

Se a vida cotidiana acontece do lado de fora da sala de atividades, em outras proporções ela também acontece fora dos muros da escola: na integração a espaços públicos, sejam ruas próximas, parques, praças ou espaços culturais do bairro ou da cidade. Entretanto, quando pensamos no tema do desemparedamento da infância em contexto pandêmico, não ignoramos o fato de que, 
mesmo com a retomada dos atendimentos presenciais nas escolas, ainda precisamos seguir com a manutenção do distanciamento social nos espaços públicos. Por isso, não incentivamos que as escolas o façam em cenários desfavoráveis para esses encontros. Por isso, optamos por não incluir, nesse momento, esse aspecto no debate.

\section{A abordagem metodológica e o contexto para o debate}

A abordagem metodológica utilizada para as análises deste artigo, em que os aspectos teóricos se articulam com uma experiência real de uma escola que se reconhece em processo de construção de uma proposta pedagógica de desemparedamento das crianças, é a da "pesquisa autobiográfica". Segundo Neves (2010), a autobiografia enquanto metodologia investigativa resulta de um exercício de relacionar uma história pessoal (ainda que vivida coletivamente com outros sujeitos) com conhecimentos científicos e acadêmicos, de modo a olhar as experiências percorridas, provocando novas perguntas e inquietações. A pesquisa autobiográfica, portanto, no campo científico da educação, preocupa-se com uma investigação qualitativa de trajetórias de professores e/ou equipes escolares enquanto ferramenta de autoformação, através das reflexões provocadas a partir da escrita de si, promovendo, ainda, uma construção da identidade docente (JESUS; TASSONI, 2017). A experiência de (auto)revisitação dos processos formativos e das práticas pedagógicas desenvolvidas pode ser uma tarefa difícil "de (auto)exposição, de (auto)avaliação, de reflexão, de estranhamento, de enfrentamento de resistências, crenças e (in)certezas" (JESUS; TASSONI, 2017, p. 227). Deste modo, os movimentos da abordagem de uma pesquisa autobiográfica não se situam em terreno de neutralidade (NEVES, 2010), pois envolvem escolhas importantes sobre o que e de quais formas narrar as experiências pessoais vividas.

A biografia escolar em questão neste artigo refere-se a uma escola pública de educação infantil de Porto Alegre com cerca de 70 vagas para crianças na faixa etária dos três aos seis anos de idade. Antes de narrar e analisar a experiência formativa e as práticas de desemparedamento desenvolvidas nessa escola, consideramos importante registrar, primeiramente, o contexto pandêmico e algumas das suas possíveis consequências em relação ao isolamento social vivenciado pela população da capital. Essa escolha justifica-se porque, para planejar e organizar uma retomada do atendimento das escolas de educação infantil (mesmo em outras cidades) é necessário ter, ainda que minimamente, uma dimensão das condições em que crianças e adultos retornam ao espaço escolar. Certamente essas condições não são as mesmas em que se iniciaria um ano letivo pós férias escolares, por exemplo, em outros tempos.

Entendemos que os anos de 2020 e 2021, ainda que em diferentes níveis conforme contexto social, político e econômico, foram marcados por um longo período de contenção corporal. $\mathrm{O}$ confinamento físico e social atingiu não apenas as crianças, mas também os profissionais que atuam nos espaços escolares. Um estudo com análises preliminares sobre as experiências das crianças em tempos de pandemia na cidade de Belo Horizonte (MG) objetivou investigar e compreender as rotinas, relações sociais, atividades, emoções e sentimentos das crianças em função da pandemia de COVID-19 (SILVA; LUZ; CARVALHO, 2021). Através de questionários on-line e entrevistas com meninos e meninas de 8 a 12 anos de idade, essa pesquisa trouxe o contexto do isolamento social a partir da escuta, pontos de vista e condições de vida das próprias crianças. Ainda que o estudo tenha sido realizado no contexto de outra capital brasileira, acreditamos que são dados que se aproximam da realidade porto-alegrense.

Em primeiro lugar, o estudo revelou que $89 \%$ das crianças responderam que estavam de fato cumprindo o isolamento social. Em segundo lugar, ao responder sobre quais eram as suas emoções, sentimentos e preocupações sobre as relações familiares e escolares, atividades realizadas em casa e sobre os próprios efeitos da pandemia em suas vidas, 
[a]s crianças revelaram, em suas falas, capacidade de resistência, consciência de suas condições de vida, dos seus direitos, responsabilidades, dos direitos de suas famílias e do contexto da crise sanitária, social e política que vivemos. Seus pontos de vista genuínos e complexos nos permitem afirmar que elas podem e devem falar por si mesmas sobre suas necessidades e demandas e que poderão contribuir muito na construção de caminhos para o enfrentamento da crise sanitária e para retomada das atividades presenciais nas escolas. (SILVA; LUZ; CARVALHO, 2021, p. 70).

Em terceiro lugar, o relatório sobre a infância em tempos de pandemia em Belo Horizonte sugere que, de acordo com as respostas das crianças, um retorno presencial à escola precisaria considerar a necessidade de um acolhimento social e subjetivo, devido às experiências de medos, angústias, ansiedades e privações em decorrência do confinamento pelo qual estivemos submetidos (SILVA; LUZ; CARVALHO, 2021).

Um confinamento que se potencializou e se intensificou devido ao distanciamento e ao isolamento orientado para que se evitasse a contaminação pelo vírus, mas que já existia, em outra medida, em muitas cidades grandes como Porto Alegre. Essa é uma capital caracterizada (1) pela ampliação da urbanização ao longo dos últimos anos, onde as áreas de lazer para as crianças estão ganhando espaço em shopping centers, afastando-as de espaços abertos públicos da cidade; (2) pelo acesso das crianças aos meios tecnológicos (ainda que com alguma dificuldade em diversas regiões de maior vulnerabilidade social), incentivado ainda mais em razão dos recursos demandados para as aulas remotas durante a suspensão dos atendimentos presenciais; (3) pelo crescimento da sensação de insegurança em espaços públicos como praças e parques, onde a violência e o uso de drogas acabam por ocupar essas áreas no lugar de crianças, famílias e comunidades.

Diante desse contexto, entendemos que é preciso reconhecer o espaço escolar externo como aquele que, além de garantir uma maior segurança sanitária para as interações devido ao ambiente aberto e com distanciamento seguro, também pode acolher esteticamente e emocionalmente as crianças, os professores e familiares. Além disso, após retornarem à escola, crianças, professores e familiares precisarão reaprender a se conectar, não mais através de salas virtuais ou transmissões de vídeos. Sem diminuir a importância e os benefícios das tecnologias como ferramentas educacionais, tão fortemente ampliadas devido ao contexto pandêmico atual, podemos nos provocar, enquanto escola e sociedade, a ampliar também as nossas conexões com o mundo natural, resgatando os seres da natureza que somos, potencializando a criatividade e a sensibilidade através da interação com esses elementos (TIRIBA, 2010).

Apresentada essa contextualização e em quais sentidos o tema dos espaços externos escolares tornam-se ainda mais relevantes nesse cenário, descrevemos a conjuntura da organização das escolas de educação infantil em Porto Alegre. Ao todo, em 2021, o município distribuiu o atendimento da etapa da educação infantil entre 35 escolas municipais de educação infantil (EMEI) com atendimento em turno integral, além de mais 7 escolas municipais de educação infantil jardins de praça (EMEI JP), com atendimento em meio turno em seis delas. 37 escolas municipais de ensino fundamental (EMEF) também atendem apenas turmas de pré-escola, dentre as quais 32 contam com uma jornada de meio turno. Além das escolas municipais, o município de Porto Alegre oferece vagas públicas em 209 escolas comunitárias de educação infantil (ECEI) em turno integral; uma escola comunitária de educação básica (ECEB) com turmas de pré-escola em turno integral; e, por fim, ainda conta com o atendimento em aproximadamente $319^{5}$ creches e pré-escolas privadas particulares (com fins lucrativos).

5 A Secretaria Municipal de Educação, enquanto responsável pelo acompanhamento, fiscalização e credenciamento dessas instituições, ainda está em processo de levantamento dos dados sobre o impacto da suspensão das aulas, durante a pandemia, ocasionando o encerramento de suas atividades. 
Desse contexto, destacamos o grupo de escolas que se caracteriza como "Jardins de Praça" (EMEI JP), já que nosso objeto de estudo autobiográfico pertence a esse grupo. Na pesquisa de Soares (2016), foram observadas três das sete EMEI JP. Uma das principais características dessas escolas é o fato de estarem localizadas em meio a praças públicas na cidade de Porto Alegre. Além disso, elas têm uma concepção histórica da sua construção (datadas entre as décadas de 20 a 40) cujo objetivo é proporcionar áreas de lazer, recreação e práticas esportivas para crianças, jovens e comunidade, se transformando, desde a década de 50, em escolas para as crianças na idade pré-escolar, majoritariamente. Professoras e diretoras entrevistadas nesse estudo (SOARES, 2016) identificaram diferentes especificidades dessas escolas em relação às demais instituições da rede: o contato com a natureza proporcionado pela localização em meio a uma praça; as interações possíveis com a comunidade por serem escolas sem muros, visíveis ao entorno; a quantidade pequena de crianças e famílias atendidas, o que oportuniza uma relação mais estreita entre todos da escola; a localização em zona urbana, tendo um público misto no que se refere à classe social, em que muitas famílias vivem em apartamentos; e a oferta de atendimento em turno parcial em sua maioria (já que grande parte das instituições de educação infantil da cidade oferecem apenas a opção do turno integral).

Esse é o contexto do presente estudo, seja do ponto de vista geral em relação a alguns dos desafios educativos e sociais devido à pandemia, seja do ponto de vista específico do perfil da instituição em que se colocará a questão do desemparedamento das crianças. Na próxima seção, uma análise autobiográfica escolar apontará em que sentidos os aspectos teóricos sobre o tema são colocados em evidência no percurso pedagógico já consolidado nesta instituição, bem como na sua continuidade, na ocasião do retorno do atendimento presencial, sendo: 1) o reconhecimento dos profissionais sobre a importância do espaço físico, principalmente nas áreas externas, para a qualificação do atendimento; 2) a descentralização da figura do adulto para a organização dos ambientes e materiais; 3) a intencionalidade educativa do planejamento para a promoção de brincadeiras e interações diversificadas nos pátios e praças. Consideramos que a seção a seguir, embora recorra a descrições de como a gestão da escola foi desenvolvendo o trabalho pedagógico para uma proposta de desemparedamento, também analisa tais ações com base nas reflexões teóricas apresentadas e, principalmente, com base nos princípios da metodologia autobiográfica.

\section{O debate na escola em questão}

A escola que estamos colocando no centro desse debate, assim como tantas outras na cidade e no país conforme apontaram as investigações de Horn (2014), apresenta uma trajetória docente em que, mesmo localizada em meio a uma praça privilegiada por espaços externos amplos e com variação de elementos naturais, ainda concentrava suas ações pedagógicas e planejamento de propostas às crianças nas salas internas de atividade. Após um longo e sistemático processo de estudo formativo da equipe de professores com a gestão da escola (inclusive tomando como referência teórica alguns dos autores citados como fundamentação de análise investigativa neste artigo), o grupo passou a reconhecer que o espaço externo escolar era uma predileção do grupo de crianças e que era necessário uma reorganização da rotina para que se oportunizassem também no pátio aprendizagens tão significativas como as que se constroem nas salas-referência. Ainda que se concordasse internamente sobre essa importância, inclusive com o suporte de momentos formativos oferecidos pela Secretaria Municipal de Educação de Porto Alegre, percebia-se a necessidade de o grupo dialogar cada vez mais sobre os direitos das crianças de aprenderem com e na natureza e de se perceberem enquanto sujeitos pertencentes a ela. No entanto, para planejar propostas para as crianças com este objetivo, os próprios adultos precisaram passar por um processo de autorreflexão sobre sua relação com a natureza. 
Assim, para uma gestão escolar que assume a função de proporcionar formação continuada, inclusive para seus profissionais, o primeiro desafio foi identificar quais as lacunas formativas da equipe para iniciar o processo de desemparedamento das crianças. Dito de outro modo, foi preciso "localizar" quais eram os "muros" (CARVALHO; FOCHI, 2016) que a organização da escola precisava derrubar. Por ser uma escola pequena, com poucas turmas e poucas salas, não havia assim tantas paredes a transpassar. Tampouco a equipe era um grupo com uma ação educativa tradicional, que desconhecia uma prática pedagógica envolvendo o protagonismo infantil ou um planejamento que articula as aprendizagens das crianças com experiências diversificadas de brincadeiras e interações. No caso específico da escola em questão, o muro que separava e impedia os professores de darem início a um desemparedamento das crianças era a necessidade de, primeiramente, iniciarem um processo de desemparedamento de si mesmos.

Para alcançar esse propósito, o grupo de professores foi envolvido em reflexões sobre as suas lembranças de brincadeiras da infância e, posteriormente, foi provocado por alguns questionamentos: (1) Nas minhas melhores lembranças de infância, como eram os ambientes em que eu brincava (abertos ou fechados)? Como eu me sentia nesses momentos? E como eram minhas experiências com a natureza, quando criança? (2) Como são as minhas experiências com a natureza hoje? Em quais circunstâncias me coloco em posição de contemplá-la ou cuidá-la? De que formas me conecto ou me deixo "sujar" com os elementos naturais? (3) Em que sentido as minhas experiências de infância e da vida adulta, em relação aos espaços externos, se refletem nas minhas ações docentes voltadas para o desemparedamento das crianças de hoje em dia?

Ao refletir individualmente sobre si mesmo e depois responder, coletivamente, essas questões, o grupo de professores pôde começar a visualizar quais eram as transformações necessárias nas ações pedagógicas cotidianas para que o espaço na educação infantil não fosse "somente um local de trabalho, um elemento a mais no processo educativo [e sim fosse] [...], antes de tudo, um recurso, um instrumento, um parceiro do professor na prática educativa." (HORN, 2003, p. 48). Para serem consolidadas enquanto uma proposta pedagógica da escola na prática, as respostas daquelas e de outras perguntas que perpassam as reflexões sobre os fazeres docentes precisam estar em consonância com o Projeto Político Pedagógico (PPP) da instituição. Esse foi o segundo movimento que a escola realizou, de modo a oferecer às crianças vivências significativas em uma escola desemparedada. Segundo consta no PPP desta escola analisada:

\footnotetext{
E o que é desemparedar?

É assumir o compromisso com as interações na natureza.

É colocar a natureza como sujeito dos processos interativos. Espaço de criatividade, autonomia e solidariedade.

É possibilitar o autoconhecimento, através da interação com os elementos da natureza. Construir uma visão de mundo pautada pelo respeito a todas as formas de vida.

É escutar os desejos das crianças, o desejo de liberdade e amor pelos espaços ao ar livre.

É levar em conta os princípios democráticos e de direito humano.
}

(PPP EMEI JP Meu Amiguinho, 2020, p. 41).

Assim, assumindo as interações das crianças com a natureza e com os espaços ao ar livre como projeto de escola e após processos formativos e contínuos com a equipe sobre o tema, analisamos que a gestão da escola promoveu a mobilização do grupo sobre a importância de considerar os espaços externos no planejamento e nas ações educativas. Sobre esse aspecto, entendemos que há a possibilidade (e, mais do que isso, há a necessidade) de envolver o próprio grupo de professores no debate interno sobre a continuidade desse projeto a partir do retorno de atividades escolares presenciais, já que as concepções já estão em processo de consolidação e algumas ações já foram implementadas. 
O desafio será justamente o de provocar no grupo, enquanto gestão da escola, o reconhecimento de que será preciso rever, reorganizar ou remodelar as ações anteriormente planejadas com o objetivo de promover a reflexão sobre as necessidades de readequação devido ao contexto pandêmico. Esse movimento implica, em certa medida, repensar a jornada na escola e ampliar as propostas em ambientes externos, mas não apenas isso. Enquanto se acolhe, de forma responsável, com diálogo e escuta, uma equipe e uma comunidade escolar em que há medos, anseios, dúvidas e expectativas latentes, em função de vivermos um período com muitas incertezas, é preciso conscientizar o grupo de que pode haver pelo menos uma certeza: a de que construir coletivamente o desemparedamento da escola, de forma participativa, se mostra, cada vez mais, importante para as crianças e para todos.

O segundo aspecto, conforme destacamos neste artigo, se refere a reconhecer o protagonismo das crianças enquanto agentes ativos na organização e transformação dos espaços escolares. Quanto a isso, constatamos que a escola em questão pôde vivenciar, preliminarmente, algumas experiências práticas de desemparedamento com as crianças, antes da suspensão do atendimento imposto pela pandemia. Alguns registros fotográficos sobre essas propostas estão evidenciados em uma videoconferência (SOARES; PORTO, 2021) apresentada na Jornada Pedagógica promovida pela SMED de Porto Alegre. Intitulados como uma série de "Aqui pode", os registros mostram as crianças em algumas brincadeiras e propostas realizadas na escola. Conforme a apresentação, nessa escola pode: experimentar, se molhar, se sujar, correr, contemplar, pesquisar/investigar/ descobrir, pintar, modelar, desenhar, descansar, plantar e cuidar, dançar, cantar e, por fim, "pode viajar nas asas da imaginação" (SOARES; PORTO, 2021). A série "Aqui pode” está relacionada com as concepções de Tiriba (2010) quando afirma que,

[a]o brincar na terra, construir castelos de areia, fantasiar segredos da floresta encantada de seus sonhos, ao imaginar enredos em que se transmutam em animais e vice-versa, as crianças vão construindo sentidos sobre a sociedade e sobre a natureza. (TIRIBA, 2010, p. 5).

Assim, sobre o aspecto da promoção de experiências significativas para que as crianças desenvolvam a autonomia e a sensação de pertencimento à natureza e aos espaços escolares, reconhecemos que, assim como as possibilidades e desafios apontados no aspecto anterior, haverá a facilidade de continuar as ações anteriormente implementadas somadas aos novos desafios de reinventá-las em um contexto que exige ainda maior cuidado de si e do outro. Nos importa salientar o quanto não podemos transformar o retorno das crianças após longos períodos de isolamento social em um impedimento para investir, na escola, na oferta de experiências às crianças que considerem nosso compromisso de conectá-las com sol, ar puro, água, terra, barro, areia, já que a escola continuará sendo, agora mais do que nunca, um espaço privilegiado onde elas "colhem suas primeiras sensações, impressões e sentimentos do viver." (TIRIBA, 2010, p. 2).

O terceiro aspecto que consideramos como necessário no estudo sobre este tema diz respeito à seleção dos materiais e à organização dos lugares nesse ambiente externo. Percebemos que esse é um elemento que ainda está em construção no processo de transformação pedagógica da escola, sendo possível identificar algumas iniciativas, como a substituição dos brinquedos de plástico por outros de madeira e metal, considerando utensílios do contexto da vida cotidiana para as brincadeiras de "casinha", por exemplo. Há, porém, a necessidade de constante reflexão e a busca de continuidade de superação da dicotomia entre atividades de sala e de pátio. Trata-se de um processo contínuo de formação em contexto que busca, através de uma constante avaliação coletiva, construir a cada dia um ambiente que ofereça descobertas e possibilidades de experiências e aprendizagens para crianças e adultos. Assim, além de se constituírem como espaços de brincar livremente e relaxar, as áreas externas nessa escola foram sendo a cada dia mais exploradas como um lugar para conversar em pares ou com toda escola, para observar os pássaros, para ouvir histó- 
rias, tornando-se, efetivamente e naturalmente na rotina escolar, um espaço de aprendizagem no qual se trabalha uma diversidade de conhecimentos (TIRIBA, 2010; BRUNER, 2013).

Cabe registrar que o distanciamento físico, tão importante para evitar o contágio da COVID-19, não significou a perda de contato entre profissionais, crianças e famílias nesta escola. Ao contrário, significou um período em que a escola necessitou se reinventar para se manter presente na vida das crianças e das famílias através de propostas de manutenção e construção de vínculo. Foram oferecidas possibilidades de exploração de elementos da natureza, na medida do possível, através de envio de kits contendo elementos como terra, sementes, argila e gravetos para as casas das crianças. As propostas desafiaram as crianças a dialogar com a natureza ao redor (existente nos lares) e a observá-la, a cantar, a ouvir histórias, a se encontrar individualmente ou em pequenos e grandes grupos com as professoras de modo virtual. Além disso, as crianças tiveram alguns momentos e espaços para conversar, virtualmente, sobre os sentimentos vividos nesse período.

Para finalizar, embora não tenha sido nosso foco de análise, acreditamos ser importante mencionar que essa proposta pedagógica, ao ser implementada, precisa começar pelo envolvimento das famílias. Algumas ações foram organizadas a fim de buscar primeiramente conquistar a confiança da comunidade escolar, ao apresentar a proposta e construir uma comunicação eficiente. As famílias foram convidadas a também brincar e participar de propostas com as crianças nos espaços externos, reconhecendo esses locais como promotores de interações e brincadeiras significativas. Também puderam acompanhar, sistematicamente, registros fotográficos e escritos sobre as propostas e aprendizagens desenvolvidas ao ar livre, expostas fisicamente na escola ou em redes sociais compartilhadas entre famílias e escola. Entendemos que esses movimentos são, em essência, aqueles indicados a qualquer projeto ou proposta pedagógica que se tenha intenção de desenvolver, já que o envolvimento e engajamento familiar são necessários para o início ou continuidade dos processos educativos. Percebemos que tal movimento facilitará, em outras circunstâncias, o envolvimento e engajamento das famílias para compreender as medidas necessárias para o retorno mais seguro e de qualidade das crianças ao espaço escolar.

\section{Um debate que não se encerra aqui}

Ao longo deste trabalho pudemos debater a relevância e as possibilidades de uma escola de educação infantil colocar em prática uma proposta pedagógica do desemparedamento, evidenciando como promover um retorno mais qualificado das crianças ao espaço escolar quando retomado o atendimento presencial nas instituições. Para isso, elencamos três aspectos de análise: 0 reconhecimento conceitual e contextual pelos profissionais sobre a importância do tema do espaço físico para a qualificação da oferta de atendimento na educação infantil, destacando os benefícios das aprendizagens ao ar livre; o foco na descentralização da figura do adulto na organização dos ambientes e materiais; a intencionalidade educativa sobre os tempos, grupos, brinquedos e materiais disponibilizados para as brincadeiras e interações.

Concluímos que existem, na escola pesquisada, algumas possibilidades e desafios para a continuidade desse projeto. Embora a escola tenha um grupo de professores com uma formação consolidada sobre a concepção de desemparedamento da infância, inclusive com ações praticadas na vida escolar cotidiana das crianças e famílias daquela comunidade, será necessário um movimento de desconstrução para que a escola seja reinventada, dentro desse mesmo projeto, para que, ao mesmo tempo que considere os protocolos sanitários e medidas para o distanciamento seguro entre crianças e profissionais na escola, não desconsidere a necessidade de manter propostas em que as crianças, como orienta a BNCC (BRASIL, 2017), possam conviver, brincar, participar, explorar, expressar e se conhecer em experiências de aprendizagem de uma vida cotidiana escolar que pode e precisa acontecer, também, "lá fora". 
A pandemia de COVID-19 está sendo um fenômeno mundial, afetando diversas áreas para além da saúde: economia, cultura, educação, entre outras. Diante desse desafio, reinventamos modos de viver, de se divertir, de aprender e de se cuidar. Em uma escola que busca aprender com e na natureza, se faz necessária a escuta e a reflexão sobre o que a pandemia pode nos ensinar. Dentre as muitas reflexões possíveis, percebe-se claramente a mensagem que a natureza nos envia sobre a inter-relação entre todos os elementos e seres. Mais uma vez a palavra cuidado torna-se o centro das discussões: cuidados de si para cuidar do outro. A responsabilidade para com este retorno dos atendimentos escolares presenciais, de forma segura e comprometida com uma educação de qualidade, precisa ser de todos. Entendemos que esse tema ainda poderá envolver muitas outras discussões e abordagens. Trata-se de um debate complexo que está apenas começando e que esperamos que possa contribuir com os movimentos de qualificação das ações pedagógicas com as crianças de zero a seis anos.

\section{Referências}

BARROS, Maria Isabel Amando de (org.). Desemparedamento da infância: a escola como lugar de encontro com a natureza. Rio de Janeiro: Criança e Natureza: Instituto Alana, 2018. Disponível em: https:/criancaenatureza.org.br/ wp-content/uploads/2018/08/Desemparedamento_infancia.pdf. Acesso em: 16 maio 2021.

BRASIL. Ministério de Educação. Secretaria de Educação Básica. Parâmetros Nacionais de Qualidade para a Educação Infantil. Brasília, DF: MEC: SEB, 2006. Disponível em: http://portal.mec.gov.br/seb/arquivos/pdf/Educinf/eduinfparqualvol1.pdf. Acesso em: 16 maio 2021.

BRASIL. Ministério de Educação. Parâmetros Básicos de Infraestrutura para Instituições de Educação Infantil. Brasília, DF: MEC: SEB, 2008. Disponível em: http://portal.mec.gov.br/seb/arquivos/pdf/Educinf/miolo_infraestr.pdf. Acesso em: 16 maio 2021.

BRASIL. Ministério da Educação. Indicadores da Qualidade na Educação Infantil. Brasília, DF: MEC: SEB, 2009a. Disponível em: http://portal.mec.gov.br/dmdocuments/indic_qualit_educ_infantil.pdf. Acesso em: 16 maio 2021.

BRASIL. Conselho Nacional de Educação. Resolução CNE/CEB n. ${ }^{\circ}$ 5, de 17 de dezembro de 2009. Fixa as Diretrizes Curriculares nacionais para a educação infantil. Diário Oficial da União: Seção 1, Brasília, DF, p. 18, 18 dez. 2009 b. Disponível em: http://portal.mec.gov.br/conselho-nacional-de-educacao/323-secretarias-112877938/orgaos-vinculados-82187207/13684-resolucoes-ceb-2009. Acesso em: 16 maio 2021.

BRASIL. Ministério da Educação. Base Nacional Comum Curricular. Brasília, DF: MEC: SEB, 2017. Disponível em: http://basenacionalcomum.mec.gov.br/ Acesso em: 16 maio 2021.

BROWN, David. O brincar, o pátio de recreio e a cultura da infância. In: MOYLES, Janet R. A excelência do brincar. Porto Alegre: Artmed, 2006. p. 63-79.

BRUNER, Jerome. Pré-escola: algumas especificidades para o espaço. In: CEPPI, Giulio; ZINI, Michele (org.) Crianças, espaços e relações: como projetar ambientes para a educação infantil. Porto Alegre: Penso, 2013. p. 145-146.

CARVALHO, Rodrigo Saballa; FOCHI, Paulo Sergio. "O muro serve para separar os grandes dos pequenos": narrativas para pensar uma pedagogia do cotidiano na educação infantil. Textura, Canoas, v. 18 n. 36 p. 153-170 jan./abr. 2016. Disponível em: http://www.periodicos.ulbra.br/index.php/txra/article/view/1949. Acesso em: 16 maio 2021.

ESCOLA MUNICIPAL DE EDUCAÇÃO INFANTIL JARDIM DE PRAÇA XXXXX. Projeto Político Pedagógico (PPP). Porto Alegre: EMEIJP, 2020.

FERNANDES, Odara de Sá; ELALI, Gleice Azambuja. Reflexões sobre o comportamento infantil em um pátio escolar: o que aprendemos observando as atividades das crianças. Paidéia, Ribeirão Preto, v. 18, n. 19, p. 41-52, 2008. Disponível em: https://www.scielo.br/scielo.php?script=sci_arttext\&pid=S0103-863X2008000100005. Acesso em: 16 maio 2021.

FORNERO, Lina Iglesias. A organização dos espaços na educação infantil. In: ZABALZA, Miguel Antônio (org.). Qualidade em Educação Infantil. Porto Alegre: Artmed, 1998. p. 229-281. 
HORN, Maria da Graça Souza. O papel do espaço na formação e transformação da ação pedagógica do educador infantil. 2003. Tese (Doutorado em Educação) - Programa de Pós-Graduação em Educação, Faculdade de Educação, Universidade Federal do Rio Grande do Sul, Porto Alegre, 2003. Disponível em: https://lume.ufrgs.br/handle/10183/1646. Acesso em: 16 maio 2021.

HORN, Maria da Graça Souza (Consultora). Estudo propositivo sobre a organização dos espaços externos das unidades do Proinfância em conformidade com as orientações desse programa e as Diretrizes Curriculares Nacionais para Educação Infantil (DCNEIs) com vistas a subsidiar a qualidade no atendimento. Ministério da Educação. Secretaria de Educação Básica. Diretoria de Currículos E Educação Integral. Coordenação Geral de Educação Infantil. Brasília, DF: MEC: SEB, 2014. Disponível em: http://portal.mec.gov.br/index.php? option=com_docman\&view=download\&alias=33051-educ-infantil-organizacao-espaco-interno-proinfancia-produto03-pdf\&category_slug=janeiro-2016-pdf\&Itemid=30192\#: : :text=Estudo\%20propositivo\%20sobre\%20a\%20organiza\%C3\%A7\%C3\%A3o,subsidiar\%20a\%20qualidade\%20no\%20 atendimento. Acesso em: 16 maio 2021.

JESUS, Deise Cristina Carvalho de; TASSONI, Elvira Cristina Martins. Escritas de mim: narrativas e a autoformação docente. Eccos Revista Científica, São Paulo, n. 44, p. 225-240, set./dez. 2017. Disponível em: https://periodicos.uninove. br/eccos/article/view/7381/3659. Acesso em: 16 maio 2021.

NEVES, Josélia Gomes. Cultura escrita e narrativa autobiográfica: implicações na formação docente. In: CAMARGO, Maria R. R. M. de (org.); SANTOS, Vivian C. C. (colab.). Leitura e escrita como espaços autobiográficos de formação [online]. São Paulo: Editora UNESP: Cultura Acadêmica, 2010. p. 123-140. Disponível em: http://books.scielo.org/id/ zz66x/pdf/camargo-9788579831263-09.pdf. Acesso em: 16 maio 2021.

SA, Jauri dos Santos; WERLE, Flávia Obino Corrêa. Infraestrutura escolar e espaço físico em educação: o estado da arte. Cadernos de Pesquisa, São Paulo, v. 47, n. 164, p. 386-413, 2017. Disponível em: https://www.scielo.br/j/cp/a/ d7HtWkVGWq4PN6xScL4wM4n/abstract/? lang=pt. Acesso em: 16 maio 2021.

SILVA, Isabel de Oliveira; LUZ, Iza Rodrigues da; CARVALHO, Levindo Diniz. Infância e pandemia na Região Metropolitana de Belo Horizonte: Primeiras análises. Belo Horizonte: UFMG/FaE/NEPEI, 2021. Disponível em: https:// infanciaconfinada.com/wp-content/uploads/2021/05/Infa\%CC\%82ncia-e-pandemia-em-Belo-Horizonte-Primeiras-ana\%CC\%81lises-19-4.pdf. Acesso em: 16 maio 2021.

SOARES, Gisele Rodrigues. "Desemparedando": potencialidades dos espaços externos em escolas de educação infantil Jardins de Praça de Porto Alegre. 2016. Trabalho de Conclusão do Curso (Especialização em Docência na Educação Infantil) - Programa de Pós-Graduação em Educação da Faculdade de Educação, Universidade Federal do Rio Grande do Sul, Porto Alegre, 2016. Disponível em: https://www.lume.ufrgs.br/handle/10183/152899\#: :text=A\%20 pesquisa $\% 20$ constatou\%20algumas\%20rela\%C3\%A7\%C3\%B5es,\%2C\%20comunidade\%2C\%20crian\%C3\%A7as\%20 e\%20Professoras. Acesso em: 16 maio 2021.

SOARES, Gisele Rodrigues; PORTO, Simoni Cezimbra. Desemparedar-se: reflexões para uma escola conectada com a natureza e com as experiências e aprendizagens ao ar livre. In: JORNADA PEDAGÓGICA A VOZ E A VEZ DO PROFESSOR, 1., 2021, Porto Alegre. Prefeitura Municipal de Porto Alegre: Secretaria Municipal de Educação. Disponível em: https://gestaopedagogica.wixsite.com/jornadapedagogica. Acesso em: 16 maio 2021.

SPINELLI, Carolina Shimomura; ZUCCO, Jucilaine; EUZÉBIO, Juliana da Silva. Educação Ambiental: refletindo sobre a relação criança e natureza na Educação Infantil. Cadernos do Aplicação, Porto Alegre, v. 33, n. 1, jan./jun. 2020. Disponível em: https://seer.ufrgs.br/CadernosdoAplicacao/article/view/104412. Acesso em: 16 maio 2021.

TIRIBA, Lea (Consultora). Crianças da Natureza. Brasília, DF: MEC: SEF, 2010. Disponível em: http://portal.mec.gov. br/docman/dezembro-2010-\%20pdf/7161-2-9-artigo-mec-criancas-natureza-lea-tiriba/file. Acesso em: 16 maio 2021.

ZABALZA, Miguel Angel. El ambiente desde una perspectiva curricular. In: GÓMEZ, José Antônio Caride (coord.). Educación ambiental: realidades y perspectivas. Santiago de Compostela: Torculo Artes Gráficas, 1991. p. 243-296.

Data de submissão: 18/05/2021

Data de aceite: $11 / 08 / 2021$ 